УДК 504.75:631.41

ВЛИЯНИЕ КОРОДРЕВЕСНЫХ ОТХОДОВ НА БИОЛОГИЧЕСКУЮ

АКТИВНОСТЬ ТЕХНОГЕННЫХ ПОВЕРХНОСТНЫХ ОБРАЗОВАНИЙ ПРИДОРОЖНЫХ ПРОСТРАНСТВ

1,2Кайгородов Р.В.

${ }^{1}$ ФГБОУ ВО «Пермский государственный национальный исследовательский университет», Пермь, e-mail: r-kaigorodov@yandex.ru;

${ }^{2}$ Тобольская комплексная научная станщия УрО РАН, Тобольск

Одной из важнейших функций и интегральным показателем состояния почв и грунтов является биологическая активность. Снижение биологической активности и повышение токсичности антропогенно нарушенных почв и почвоподобных образований в транспортной зоне обусловлено нарушениями физикохимических свойств и накоплением загрязняющих веществ. В дополнение к диагностике экологического состояния техногенных поверхностных образований (далее ТПО) и степени токсичности необходима разработка способов восстановления их экологических функций, включая повышение биологической активности и снижение уровня токсичности. Одним из направлений может служить внесение в ТПО органических веществ для оптимизации физико-химических и биологических функций грунта. Источником органического вещества для ТПО могут служить коро-древесные отходы (далее КДО), размещенные в больших объемах на короотвалах целлюлозно-бумажных предприятий. Целью данной работы было исследование воздействия КДО на биологическую активность и подвижность токсичных металлов в ТПО придорожных пространств. В настоящей работе стандартными методами изучен химический состав КДО: содержание азота, углерода, фосфора, кальция и магния, показатели кислотности. Установлена изменчивость агрохимических свойств КДО в зависимости от глубины залегания слоя в короотвале и выделены слои (глубина 5,5-9,0 м) с оптимальными свойствами. Методом фитотестирования изучена биологическая активность и уровень токсичности КДО. Дана оценка влияния КДО на биохимические и токсикологические свойства ТПО придорожных пространств на примере грунтов придорожных пространств внегородских автомагистралей. Методом биотестирования на проростках кресс-салата (Lepidium sativum L.) установлено повышение биологической активности ТПО за счет внесения КДО в дозировках 5 и $15 \%$ по массе. Показано снижение подвижности свинца в ТПО при внесении в них КДО.

Ключевые слова: техногенные поверхностные образования транспортной зоны, коро-древесные отходы, фитотестирование, биологическая активность, биохимические свойства, уровень кислотности, подвижность свинца и кадмия

\title{
IMPACT OF WOOD WASTE ON BIOLOGICAL ACTIVITY OF TECHNOGENIC SURFACE FORMATIONS OF ROADSIDE AREAS

\author{
${ }^{1,2}$ Kaygorodov R.V. \\ ${ }^{1}$ Perm State University, Perm, e-mail: r-kaigorodov@yandex.ru;
} \\ ${ }^{2}$ Tobolsk complex scientific station of the Ural Branch of the RAS, Tobolsk
}

\begin{abstract}
One of the most important functions and an integral indicator of the ecological state of soils and technogenic surface formations is biological activity. Reduced biological activity and toxicity of degraded soils and technogenic surface formations may be due to both their adverse properties and a variety of pollutants (heavy metals, salts, petroleum products). In addition to diagnosing the state of technogenic surface formations and the degree of toxicity, it is necessary to develop ways to restore their ecological functions, including increasing biological activity and reducing toxicity. One of the directions can be the introduction of organic substances into technogenic surface formations to optimize the physical, chemical and biological functions of the soil. Source of organic substance for technogenic surface formations may serve as wood waste from the storage of pulp-paper industry. The aim of this work was to study the impact of wood waste on the biological activity and mobility of toxic metals in technogenic surface formations of roadside areas. In samples of wood waste and technogenic surface formations by standard methods were analyzed content of nitrogen, carbon, phosphorus, calcium, magnesium and acidity level. Biological activity of wood waste and technogenic surface formations was determined by phytotesting. Change of chemical properties of wood waste with depth was established. The layers $(5,5-9,0 \mathrm{~m})$ with optimal properties were selected. The impact of wood waste on the biochemical and toxicological properties of technogenic surface formations in roadside areas was assessed on the example of soils of roadside spaces of outside urban highways. The method of biotesting with sprouts of cress (Lepidium sativum L.) established an increase in the biological activity of technogenic surface formations due to the introduction of wood waste in dosages of 5 and $15 \%$ by weight. Shown to reduce the mobility of lead in technogenic surface formations after supplementation of wood waste.
\end{abstract}

Keywords: technogenic surface formations of transport zone, wood waste, phytotesting, biological activity, biochemical properties, acidity level, mobility of lead and cadmium

Значительная часть почвенного покрова природно-техногенных и техногенных экосистем представлена деградированными почвами и ТПО. Их состав, свойства и эко- логические функции существенно нарушены по сравнению с естественными почвами. В одной из наших работ [1] дана оценка биологической активности ТПО на приме- 
ре литостратов и органолитостратов придорожных пространств автомагистралей внегородских территорий, пролегающих в Тюменской области. Фитотестирование этих ТПО показало низкую биологическую активность и их неудовлетворительное экологическое состояние. В исследованных грунтах была выявлена высокая изменчивость интенсивности эмиссии $\mathrm{CO}_{2}$ на разных участках дорог и снижение активности фермента каталазы по сравнению с грунтами внутригородских придорожных территорий. Низкое содержание органического вещества и гумуса, а также кислая и слабокислая среда ТПО обуславливают увеличение подвижности ионов свинца и кадмия.

В настоящей работе исследована возможность повышения биологической активности и оптимизация экологических свойств ТПО путем внесения в них органических материалов.

В качестве источников органического вещества для ТПО нами изучены кородревесные отходы целлюлозно-бумажного производства.

При подготовке древесины к производству бумаги на целлюлозно-бумажных комбинатах образуются КДО, обладающие IV классом опасности для объектов окружающей среды и размещаемые в больших объемах на короотвалах.

Отходы деревообработки представляют собой древесные остатки, состоящие из фракций разного размера, обладающие различным характером и степенью разложения, которое протекает за счет естественных микробиологических процессов трансформации органических остатков растительного происхождения.

Накопление больших объемов КДО, оказывающих негативное влияние на объекты окружающей среды (грунтовые воды, почвенный покров), требует разработки способов их безопасной утилизации, переработки и рационального использования [2]. Повышение биологической активности ТПО и снижение подвижности токсичных элементов, относящихся к важнейшим факторам устойчивости придорожных экосистем и к их снитарно-гигиеническим функциям, имеет особенно большое значение в решении геоэкологических задач в природоохранных зонах водоемов вблизи автомагистралей.

Цель исследования: изучение влияния КДО на биологическую активность ТПО придорожных пространств вне городских территорий в пределах водоохранных зон. В ходе работы были изучены химические свойства КДО. В модельных экспериментах методом фитотестирования исследовано воздействие КДО на биологическую активность ТПО и подвижность в них ионов кадмия и свинца.

Новизной и практической значимостью работы является исследование возможностей использования органогенных отходов целлюлозно-бумажной промышленности для повышения устойчивости техногенных грунтов в водоохранных зонах, прилегающих к автомагистралям внегородских территорий.

\section{Материалы и методы исследования}

Образцы ТПО придорожных пространств были отобраны в июле 2017 г. вблизи (удаление 5 м от края дорожного полотна) автомобильных дорог Тюменской области. Вдоль исследуемых трасс в местах пересечения водоохранных зон малых и средних рек было заложено 7 участков для отбора образцов ТПО. На каждом участке отбирали по пять точечных проб грунта на расстоянии 1 м друг от друга и объединяли в смешанный образец массой по 0,5 кг. Исследуемые грунты относились к группе натурфабрикатов: подгруппы литостратов (участки № $1,2,5,7)$ и органолитостратов (участки № 3, 4, 6) [3]. Образцы перед хранением высушены до воздушно-сухого состояния, находились на хранении в сухих, темных, прохладных условиях в плотно закрытой таре, что обеспечило стабильность их состава и свойств и репрезентативность исследований в модельных экспериментах.

Образцы КДО отбирали из короотвалов целлюлозно-бумажного производства из слоев с разной глубиной: слой № $1-0$ 3,5 м, слой № $2-3,5-5,5$ м, слой № 3 5,5 - 9 м, слой № 4 - более 9 м. Для исследований с помощью сита отбирали фракцию КДО размером менее 2 мм.

Исследуемые ТПО и КДО послужили материалами для постановки модельных экспериментов по оценке оптимизации биологической активности и снижению подвижности токсичных элементов

Постановка эксперимента с КДО. В каждый из семи вариантов ТПО (по участкам отбора) вносили дозу КДО из слоя № 3 (глубина 5,5-9,0 м) с оптимальными агрохимическими свойствами, фракция размером менее 2 мм из расчета 5 и $15 \%$ по масce, тщательно перемешивали, увлажняли и выдерживали 1 сутки. В подготовленный грунт высевали семена кресс-салата по 0,5 г в каждый вариант и проводили полив дис- 
тиллированной водой. В качестве контроля использовали вермикулит и полив раствором Кнопа.

Анализ химических свойств КДО проводили стандартными методами: содержание общего азота - методом Къельдаля, содержание фосфатов - методом Кирсанова, содержание органического углерода - методом Тюрина. Содержание ионов кальция и магния в водных вытяжках определяли методом пламенной фотометрии.

Оценку биологической активности исследуемых ТПО, КДО и их смесей проводили в соответствии с методикой «Способ оценки биологической активности и токсичности почв и техногенных почвогрунтов» патент № 2620555. В качестве тесткультуры применяли кресс-салат (Lepidium sativum L.), в контрольном варианте проростки выращивали на вермикулите с подкормкой раствором Кнопа. Подвижность ионов свинца и кадмия анализировали в водных вытяжках с помощью ионселективных электродов на иономере «Экотест-120». Подвижность ионов металла выражали отрицательным десятичным логарифмом молярной концентрации соответствующего иона $\left(-\log \left[\mathrm{Cd}^{2+}\right]\right)$ и $\left(-\log \left[\mathrm{Pb}^{2+}\right]\right)$.

Анализы проводили в лабораториях физиологии и биохимии растений кафедры физиологии растений и экологии почв ПГНИУ.

Статистическую обработку данных проводили в программе Past 3.16 методами описательной статистики, дисперсионного и корреляционного анализа. Достоверность опыта оценивали по критерию Стьюдента, достоверность различий между вариантами проверяли с помощью показателя наименьшей существенной разности (НСР).

\section{Результаты исследования и их обсуждение}

В образцах КДО анализировали актуальную, обменную и гидролитическую кис- лотность. Уровень кислотности во многом определяет характер микробиологических процессов, влияет на подвижность токсичных металлов, на рост и развитие растений. Исследованные КДО по уровню актуальной кислотности являются сильнокислыми (табл. 1). Данные по обменной кислотности $\left(\mathrm{pH}_{\mathrm{KCl}}\right)$ и гидролитической кислотности (табл. 1) показывают необходимость в известковании КДО для устранения избыточной кислотности и оптимизации физико-химических свойств.

Для оценки состава, качества и степени разложения органогенных субстратов, например торфа или КДО, используется содержание органического углерода, азота и их соотношение. Данные агрохимического анализа КДО приведены в табл. 2.

Содержание органического углерода служит показателем обеспеченности грунта органическим веществом и энергией, необходимыми для функционирования биологической фазы и обеспечивающих устойчивость субстрата к неблагоприятным факторам. Для наиболее плодородных почв и грунтов характерно содержание органики на уровне 40-50\% [4]. В образах исследованных КДО доля органического углерода находилась в пределах от 17,6 до 29,1\%.

Содержание азота показывает степень разложения органических остатков в грунтах и определяет их агрохимическую ценность. Высокое содержание азота было характерно для верхних и средних слоев большинства скважин исследованных короотвалов. В КДО соотношение азота к углероду сильно варьировало в диапазоне от 1:32 до 1:75 в связи с разной долей органического углерода Оптимальным является отношение $\mathrm{C}: \mathrm{N}$ не более 1:40 [4]. При последующем разложении КДО можно ожидать постепенного повышения содержания общего азота и оптимизации его соотношения с углеродом.

Показатели кислотности КДО

Таблица 1

\begin{tabular}{|l|c|c|c|}
\hline \multicolumn{1}{|c|}{ Образец } & $\begin{array}{c}\text { Актуальная кислотность } \\
\mathrm{pH}_{\text {вод }}\end{array}$ & $\begin{array}{c}\text { Обменная кислотность } \\
\mathrm{pH}_{\mathrm{KCl}}\end{array}$ & $\begin{array}{c}\text { Гидролитическая } \\
\text { Кислотность, мг-экв/100 г }\end{array}$ \\
\hline Слой 1 (верхний) & 5,72 & $\begin{array}{c}4,71 \text { среднекислая, средняя } \\
\text { потребность в известковании }\end{array}$ & 10,7 \\
\hline Слой 2 & 5,19 & $\begin{array}{c}4,42 \text { среднекислая, средняя } \\
\text { потребность в известковании }\end{array}$ & 13,4 \\
\hline Слой 3 & 5,32 & $\begin{array}{c}4,57 \text { среднекислая, средняя } \\
\text { потребность в известковании }\end{array}$ & 12,3 \\
\hline Слой 4 (нижний) & 5,44 & $\begin{array}{c}4,72 \text { среднекислая, средняя } \\
\text { потребность в известковании }\end{array}$ & 11,8 \\
\hline
\end{tabular}


Химический состав КДО

\begin{tabular}{|l|c|c|c|c|c|c|}
\hline \multicolumn{1}{|c|}{ Образец } & $\mathrm{C}, \%$ & $\mathrm{~N}, \%$ & $\mathrm{C}: \mathrm{N}$ & $\mathrm{P}_{2} \mathrm{O}_{5}, \mathrm{M \Gamma} / \mathrm{\kappa} \Gamma$ & $\mathrm{Ca}^{2+}, \mathrm{M \Gamma} / \mathrm{\kappa \Gamma}$ & $\mathrm{Mg}^{2+}, \mathrm{M \Gamma} / \mathrm{\kappa} \Gamma$ \\
\hline Слой 1 (верхний) & 29,1 & 0,61 & 48 & 94,4 & 340 & 108 \\
\hline Слой 2 & 27,2 & 0,36 & 75 & 103,0 & 344 & 101 \\
\hline Слой 3 & 26,2 & 0,59 & 44 & 94,4 & 358 & 105 \\
\hline Слой 4 (нижний) & 17,6 & 0,55 & 32 & 91,6 & 321 & 98 \\
\hline
\end{tabular}

Агрохимическую ценность КДО определяет также содержание фосфора, который является одним из важнейших минеральных элементов питания растений. Для почв Нечерноземной полосы оптимальное содержание подвижного фосфора составляет 100-150 мг/кг почвы [4]. В исследованных КДО установлен очень высокий уровень содержания подвижных фосфатов, близкий к оптимальным значениям обеспеченности субстратов фосфором (табл. 2).

Необходимыми для нормального роста и развития растений являются элементы кальций и магний. Кальций регулирует структурное состояние почвогрунтов и играет важную роль в формировании их агрофизических и агрохимических свойств, устраняет негативное влияние избыточной кислотности, токсичных элементов, обеспечивает устойчивость к эрозии. В исследуемых КДО содержание кальция на 25$50 \%$ ниже нормального уровня, который в обеспеченных почвах составляет 420750 мг/кг [4], что требует дополнительного внесения кальция (известковая или доломитовая мука) для улучшения химических и физических свойств.

При использовании субстратов короотвала в качестве почвогрунтов наиболее оптимальными являются верхние (0-3,5 м) и средние (3,5-7,5 м) слои. Глубинные слои (более 9 м) могут использоваться для производства компостов и других органических удобрений, т.е. требуют дополнительной переработки.

Фитотестирование исследуемых КДО показало их удовлетворительное состояние по росту (снижение на $26 \%$ относительно контроля) и по биомассе (снижение на $26 \%$ относительно контроля).

В исследуемые ТПО были внесены дозы КДО в размере 5 и $15 \%$ по массе и проведено фитотестирование биологической активности полученных субстратов.

Как видно из табл. 3 , наблюдалось достоверное увеличение роста и биомассы тесткультуры (проростки кресс-салата) на ТПО из группы литостратов некоторых участков (№ 1, 2 и 5) после добавления КДО в обеих дозировках. На участке № 7 изменение ростовых показателей вызвано внесением КДО только в размере $15 \%$. На остальных участках, относящихся к органолитостратам, внесение КДО не приводило к увеличению роста и биомассы тест-культуры. Таким образом, наибольший эффект в плане повышения биологической активности следует ожидать от внесения КДО в грунты обедненные органическим веществом, например абралиты и литостраты.

Низкая доля органического вещества, высокая кислотность, пониженная биологическая активность обуславливают высокую подвижность токсичных металлов и их негативное токсическое действие на экологическое состояние придорожных территорий и вызывают опасность загрязнения прилегающих экосистем $[5,6]$.

В дополнение к фитотестированию в исследуемых ТПО изучено влияние внесения КДО на поведение токсичных элементов: свинца и кадмия. Подвижность свинца и кадмия выражали отрицательным десятичным логарифмом молярной концентрации ионов в водной вытяжке $\left(-\log \left[\mathrm{Pb}^{2+}\right]\right.$, $\left.-\log \left[\mathrm{Cd}^{2+}\right]\right)$, т.е. увеличение значений логарифма концентрации свидетельствует о снижении содержания водорастворимых форм ионов, т.е. об уменьшении их подвижности и фитотоксичности. При внесении КДО в исследуемые ТПО на всех участках, за исключением № 6 и 7, наблюдалось снижение подвижности ионов свинца.

В то же время подвижность ионов кадмия, обладающих меньшим сродством к органическому веществу по сравнению со свинцом, достоверно не изменилась при внесении КДО в образцы ТПО из всех исследуемых участков (табл. 4). Вероятно, подвижность ионов кадмия в ТПО может быть ограничена внесением известковых материалов на фоне внесения органогенных субстратов, что входит в программу наших дальнейших исследований. 
Таблица 3

Ростовые показатели и биомасса тест-культуры на исследованных ТПО до и после внесения КДО

\begin{tabular}{|c|c|c|c|c|c|c|}
\hline \multirow[t]{3}{*}{ № участка } & \multicolumn{3}{|c|}{ Рост, см } & \multicolumn{3}{|c|}{ Биомасса, г } \\
\hline & \multicolumn{3}{|c|}{ Доза КДО, \% } & \multicolumn{3}{|c|}{ Доза КДО, \% } \\
\hline & без КДО & 5 & 15 & без КДО & 5 & 15 \\
\hline № 1 & 1,65 & 2,34 & 2,60 & 0,0084 & 0,0140 & 0,0150 \\
\hline № 2 & 1,37 & 2,80 & 2,80 & 0,0078 & 0,0130 & 0,0170 \\
\hline № 3 & 2,42 & 1,88 & 2,46 & 0,0131 & 0,0100 & 0,0120 \\
\hline № 4 & 2,79 & 2,55 & 2,89 & 0,0158 & 0,0120 & 0,0160 \\
\hline № 5 & 1,10 & 2,44 & 2,71 & 0,005 & 0,0100 & 0,0120 \\
\hline № 6 & 3,19 & 2,79 & 2,94 & 0,0178 & 0,0150 & 0,0120 \\
\hline № 7 & 1,95 & 1,96 & 2,62 & 0,0120 & 0,0170 & 0,0220 \\
\hline $\mathrm{HCP}$ & \multicolumn{3}{|c|}{0,30} & \multicolumn{3}{|c|}{0,0060} \\
\hline
\end{tabular}

Таблица 4

Подвижность ионов свинца и кадмия в исследованных ТПО до и после внесения КДО

\begin{tabular}{|c|c|c|c|c|c|c|}
\hline \multirow{2}{*}{ № участка } & \multicolumn{3}{|c|}{$-\log \left[\mathrm{Pb}^{2+}\right]$} & \multicolumn{3}{c|}{$-\log \left[\mathrm{Cd}^{2+}\right]$} \\
\cline { 2 - 7 } & \multicolumn{3}{|c|}{ Доза КДО,\% } & \multicolumn{3}{c|}{ Доза КДО,\% } \\
\cline { 2 - 7 } & без КДО & 5 & 15 & без КДО & 5 & 15 \\
\hline № 1 & 5,2 & 7,3 & 6,7 & 4,6 & 5,2 & 4,3 \\
\hline № 2 & 6,9 & 7,4 & 7,4 & 5,3 & 5,2 & 5,3 \\
\hline № 3 & 6,7 & 8,2 & 7,7 & 5,2 & 5,3 & 5,4 \\
\hline № 4 & 6,8 & 7,0 & 7,5 & 5,3 & 5,3 & 5,2 \\
\hline № 5 & 5,2 & 6,7 & 7,8 & 4,8 & 5,1 & 4,8 \\
\hline № 6 & 7,6 & 7,6 & 7,7 & 5,4 & 5,4 & 5,3 \\
\hline № 7 & 7,1 & 6,8 & 6,8 & 5,4 & 5,2 & 5,1 \\
\hline НСР & \multicolumn{7}{|c|}{0,5} & & 0,3 & \\
\hline
\end{tabular}

\section{Заключение}

Таким образом, установлено, что внесение КДО в техногенные поверхностные образования приводит к повышению их биологической активности и достоверному снижению подвижности свинца на большинстве исследуемых участков придорожных пространств. В ТПО из группы органолитостратов внесение КДО не вызывает эффективного увеличения биологической активности, однако приводит к снижению подвижности ионов свинца.

В качестве практических рекомендаций можно предложить следующее:

- для повышения биологической активности ТПО и снижения подвижности ионов свинца в придорожных пространствах вблизи водоохранных зон оптимальными свойствами обладают срединные слои короотвалов целлюлозно-бумажного производства (глубина 5,5-9,0 м) по сравнению с верхними и более глубокими слоями;

- для внесения необходимо использовать фракции КДО диаметром менее 2 мм в дозах 5 и 15\% (по массе) ТПО придорожных пространств, относящихся к литостратам, т.е. обладающих резким дефицитом органического вещества.

В целом внесение органогенных отходов целлюлозно-бумажной промышленности в минеральные техногенные грунты можно рассматривать в качестве одной из мер управления современными ландшафтами, направленной на улучшение санитарно-гигиенического состояния водоохранных зон вблизи автомагистралей.

Статья подготовлена при финансовой поддержке Минобрнауки РФ в рамках темь фундаментальных научных исследований "Антропогенная трансформация пойменных экосистем Обь-Иртышского бассейна» (№ AAAA-A19-119012190088-0).

\section{Список литературы / References}

1. Кайгородов Р.В., Попова Е.И. Биологическая активность техногенных поверхностных образований транспортной зоны вне урбанизированных территорий Тюменской области // Успехи современного естествознания. 2018. № 12 (1). C. 136-142. DOI 10.17513/use.36987. 
Kaygorodov R.V., Popova E.I. Biological activity of technogenic surface formations in the transport zone outside urban areas in Tumen region // Advances in current natural sciences. 2018. № 12 (1). Р. 136-142 (in Russian).

2. Коротаев В.Н., Жилинская Я.А., Ширинкина Е.С. Технологические подходы к использованию продуктов механобиологической переработки отходов для рекультивации нарушенных земель на урбанизированных территориях // Защита окружающей среды в нефтегазовом комплексе 2010. № 6. C. 9-14.

Korotaeva V.N., Zhilinskaja Ya.A., Shirinkina E.S. Technological approaches to the use of products of mechanical-biological processing of waste for restoration of disturbed lands in urban areas // Zashita okruzhajushej sredy v neftegazovom komplexe. 2010. № 6. P. 9-14 (in Russian).

3. Классификация и диагностика почв России. Смоленск: Ойкумена, 2004. 343 с.

Classification and diagnostics of Russian soils. Smolensk: Ojkumena, 2004. 343 p. (in Russian).
4. Каменщикова В.И., Еремченко О.З., Шестаков И.Е. Биохимическая активность почв г. Перми // Вестник Пермского университета. Серия: Биология. 2011. № 2. С. 38-40.

Kamenshikova V.I., Eremchenko O.Z., Schestakov I.E. Biochemical activity of soil of Perm city // Vestnic Permskogo universiteta. Seriya: Biologija. 2011. № 2. P. 38-40 (in Russian).

5. Еремченко О.3., Шестаков И.Е., Каменщикова В.И. Эколого-биологические свойства урбаноземов г. Перми // Вестник Удмуртского университера. Серия: Биология. Науки о Земле. 2010. № 4. С. 56-63.

Eremchenko O.Z., Schestakov I.E., Kamenshikova V.I. Ecological-biological properties of urban soil of Perm city // Vestnik Udmurtskogo universiteta. Seriya: Biologija. Nauki o zemle. 2010. № 4. P. 56-63 (in Russian).

6. Коркина Е.А. Самовосстановление нарушенных техногенезом почв Среднего Приобья: монография / Отв. ред. Г.Н. Гребенюк. Нижневартовск: Изд-во НВГУ, 2015. 158 с.

Korkina E.A. Self-healing of soils disturbed by technogenesis of the Middle Ob region: Monograph / Otv. red. G.N. Grebenyuk. Nizhnevartovsk: NVGU, 2015. 158 p. (in Russian). 